\title{
Mixed matrix membranes based on MIL-101 metal-organic frameworks in polymer of intrinsic microporosity PIM-1.
}

DOI:

10.1016/j.seppur.2018.11.055

\section{Document Version}

Accepted author manuscript

Link to publication record in Manchester Research Explorer

\section{Citation for published version (APA):}

Khdhayyer, M., Bushell, A. F., Budd, P., Attfield, M., Jiang, D., Burrows, A. D., Esposito, E., Bernardo, P., Monteleone, M., Fuoco, A., Clarizia, G., Bazzarelli, F., Gordano, A., \& Jansen, J. C. (2019). Mixed matrix membranes based on MIL-101 metal-organic frameworks in polymer of intrinsic microporosity PIM-1. Separation and Purification Technology, 212, 545-554. https://doi.org/10.1016/j.seppur.2018.11.055

\section{Published in:}

Separation and Purification Technology

\section{Citing this paper}

Please note that where the full-text provided on Manchester Research Explorer is the Author Accepted Manuscript or Proof version this may differ from the final Published version. If citing, it is advised that you check and use the publisher's definitive version.

\section{General rights}

Copyright and moral rights for the publications made accessible in the Research Explorer are retained by the authors and/or other copyright owners and it is a condition of accessing publications that users recognise and abide by the legal requirements associated with these rights.

\section{Takedown policy}

If you believe that this document breaches copyright please refer to the University of Manchester's Takedown Procedures [http://man.ac.uk/04Y6Bo] or contact uml.scholarlycommunications@manchester.ac.uk providing relevant details, so we can investigate your claim.

\section{OPEN ACCESS}




\title{
Mixed matrix membranes based on MIL-101 metal-organic frameworks in polymer of intrinsic microporosity PIM-1.
}

Muhanned Khdhayyer ${ }^{1}$, Alexandra F. Bushell ${ }^{1}$, Peter M. Budd ${ }^{1}$, Martin P. Attfield*1, Dongmei Jiang, Andrew D. Burrows ${ }^{2}$, Elisa Esposito ${ }^{3}$, Paola Bernardo ${ }^{3}$, Marcello Monteleone, Alessio Fuoco ${ }^{3}$, Gabriele Clarizia ${ }^{3}$, Fabio Bazzarelli, Amalia Gordano ${ }^{3}$, Johannes C. Jansen ${ }^{3}$

1 School of Chemistry, University of Manchester, Manchester M13 9PL, UK. E-mail: m.attfield@manchester.ac.uk

2 Department of Chemistry, University of Bath, Claverton Down, Bath BA2 7Y, UK

${ }^{3}$ Institute on Membrane Technology, ITM-CNR, Via P. Bucci 17/C, 87036 Rende (CS), Italy. E-mail: e.esposito@itm.cnr.it

\begin{abstract}
This work presents a study on mixed matrix membranes (MMMs) of the polymer of intrinsic microporosity PIM-1, embedding the crystalline Cr-terephthalate metal-organic framework (MOF), known as MIL-101. Different kinds of MIL-101 were used: MIL-101 with an average particle size of ca. $0.2 \mu \mathrm{m}$, NanoMIL-101 (ca. $50 \mathrm{~nm}$ ), ED-MIL-101 (MIL-101 functionalized with ethylene diamine) and $\mathrm{NH}_{2}$-MIL-101 (MIL-101 synthesized using 2aminoterephthalic acid instead of terephthalic acid). Permeability, diffusion and solubility coefficients and their corresponding ideal selectivities were determined for the gases $\mathrm{He}, \mathrm{H}_{2}$, $\mathrm{O}_{2}, \mathrm{~N}_{2}, \mathrm{CH}_{4}$ and $\mathrm{CO}_{2}$ on the "as-cast" samples and after alcohol treatment. The performance of the MMMs was evaluated in relation to the Maxwell model. The addition of $\mathrm{NH}_{2}-\mathrm{MIL}-101$ and ED-MIL-101 does not increase the membrane performance for the $\mathrm{CO}_{2} / \mathrm{N}_{2}$ and $\mathrm{CO}_{2} / \mathrm{CH}_{4}$ separation because of an initial decrease in selectivity at low MOF content, whereas the $\mathrm{O}_{2}$ and $\mathrm{N}_{2}$ permeability both increase for $\mathrm{NH}_{2}-\mathrm{MIL}-101$. In contrast, MIL-101 and NanoMIL101 cause a strong shift to higher permeability in the Robeson diagrams for all gas pairs, especially for $\mathrm{CO}_{2}$, without significant change in selectivity. Unprecedented $\mathrm{CO}_{2}$ permeabilities up to 35,600 Barrer were achieved, which are among the highest values reached with PIM-1 based mixed matrix membranes. For various gas pairs, the permeability and selectivity were far above the Robeson upper bound after alcohol treatment. Short to
\end{abstract}


medium time aging shows that alcohol treated samples with MIL-101 maintain a systematically higher permeability in time. Mixed gas permeation experiments on an aged ascast sample with 47 vol\% MIL-101 reveal that the MMM sample maintains an excellent combination of permeability and selectivity, far above the Robeson upper bound $\left(\mathrm{CO}_{2}=3,500-3,800\right.$ Barrer, $\left.\mathrm{CO}_{2} / \mathrm{N}_{2}=25-27 ; \quad \mathrm{CO}_{2} / \mathrm{CH}_{4}=21-24\right)$. This suggests good perspectives for these materials in thin film composite membranes for real applications.

Keywords: Mixed matrix membranes, PIM-1, MOFs, MIL-101, gas separation, Maxwell model

\section{Introduction}

Polymer membrane-based processes are recognized as low-cost and environmentally friendly alternatives to conventional gas separation processes [1]. Many polymer membranes have been investigated for gas separations, showing a trade-off between permeability and selectivity. Polymers of intrinsic microporosity (PIMs), combining a high free volume [2] with good processability, are receiving particular attention for membrane gas separation applications. The first representative of the PIM family was referred to as PIM-1 by Budd and McKeown [3,4]. PIM-1 is a spirobisindane ladder-type polymer as shown in Fig. 1A, with rigid polymer backbone and large free volume elements. Its permselectivity was used to define the 2008 Robeson upper bound, for important gas pairs such as $\mathrm{CO}_{2} / \mathrm{N}_{2}$ and $\mathrm{CO}_{2} / \mathrm{CH}_{4}$, as a consequence of its large and interconnected free volume [5-8]. These materials are prone to physical aging, which is a reduction over time of available free volume and, thus, of the permeability [9]. Even if the aging is often coupled with an improvement in the selectivity, it is not always desired because it does not allow stable operation over time [9-11]. Dimensionally more stable porous materials, such as zeolites or MOFs [12], do not have the same problem of physical aging and often combine high permeability and high selectivity. However, they are generally brittle and difficult to prepare in large areas without defects. Instead, mixed matrix membranes (MMMs) [13-17], based on inorganic or metal-organic particles dispersed in polymers, have the potential to combine synergistically the good separation performance of the fillers and the mechanical resistance of the polymers, provided that there is a good dispersion of the filler within the membrane [12,18-22]. Several 
nanoporous materials have been investigated for this purpose in PIM-1, including zeolites [23] and carbon nanotubes [24], but also the non-porous graphene [25] and inorganic particles [26]. More recently, the crystalline MOFs have attracted significant attention [2730]. These three-dimensional porous coordination polymers have versatile architectures, which combine an open porosity, large inner surface area and tuneable pore sizes and topologies $[31,32]$. In many cases, size selective gas transport in the MMMs is related to the pore size of MOFs, which can promote more readily the passage of small gases. While the growth of HKUST-1 and the zeolitic imidazolate framework, ZIF-8, on top of PIM-1 films lead to a reduction of the permeability [33], the dispersion of ZIF-8 in the PIM-1 matrix was found to increase the free volume, leading to higher gas permeabilities and diffusion coefficients, as well increased selectivities for gas pairs with substantial differences in kinetic diameter, such as $\left(\mathrm{H}_{2} / \mathrm{N}_{2}\right)$ or $\left(\mathrm{H}_{2} / \mathrm{CH}_{4}\right)$ [34]. A crucial aspect in the design of suitable MMMs is the combination of materials with a good affinity, because an interaction at the interface between the polymer matrix and the MOF particles can significantly affect the gas transport properties. Owing to the organic linkers connecting the transition metals and transition metal oxides in MOFs, a better compatibility with the continuous polymeric matrix is expected when using MOFs as fillers, rather than inorganic zeolites, in MMMs. Indeed, methods like chemical surface modification or functionalization of the MOF particles have been adopted to promote the compatibility between the fillers and the polymer matrix in order to enhance the gas separation performance of the MMM. The permeability of PIM-1 was increased from 8210 to 10,700 Barrer by the addition of functionalized UiO-66, maintaining high selectivity also in mixed gas permeation experiments [35].

The present work reports novel MMMs based on PIM-1, in which the dispersed phase consists of crystalline Cr-based MIL-101, first synthesized by Férey et al. [36] and indicated by Yampolskii et al. as a promising filler in PIM-1 [29]. MIL-101 has been dispersed in different polymers for the fabrication of MMMs for several applications. Recently, Jung et al. loaded MIL-101 into polystyrene- b- polybutadiene- b- polystyrene (SBS) block copolymer obtaining encouraging results for olefin/paraffin separation [37]. In pervaporation, MMMs based on modified $\mathrm{SO}_{3} \mathrm{H}-\mathrm{MIL}-101$ in the hydrophilic polymer poly(vinyl alcohol) have shown large selectivities and permeabilities for water/ethylene glycol separation performance, compared with the other reported membranes [38]. In gas separation, the 
$\mathrm{CO}_{2} / \mathrm{CH}_{4}$ selectivity for polysulfone was enhanced by the synergistic addition of MIL-101 and ZIF-8 [39].

MIL-101 (framework $\left[\mathrm{Cr}_{3} \mathrm{O}(\mathrm{F} / \mathrm{OH})\left(\mathrm{H}_{2} \mathrm{O}\right)_{2}\left(\mathrm{O}_{2} \mathrm{CC}_{6} \mathrm{H}_{4} \mathrm{CO}_{2}\right)_{3}\right]$ ) has a framework structure consisting of two cages with inner free cage diameters of $2.9 \mathrm{~nm}$ and $3.4 \mathrm{~nm}$ (Fig. 1B). Entrance to these cages is through pentagonal rings of $1.2 \mathrm{~nm}$ diameter and hexagonal rings with $1.5 \mathrm{~nm} \times 1.6 \mathrm{~nm}$ diameters that are large enough to admit gases and small organic molecules (Fig. 1C) [40].

The aim of this work is the demonstration that the excellent properties of PIM-1 can be further enhanced by the addition of MOFs with a very open pore structure. Different kinds of MIL-101 were dispersed in the PIM-1 matrix to study the effect of the particle size of MIL101 and the effect of the chemical nature of amine- or ethylene diamine-functionalized MIL101 on the MMM performance. The use of similar MOFs with different size and functionalization enabled the identification of some critical factors determining the MMM performance. Results for two batches of PIM-1 with different molar mass highlighted the importance of the continuous phase. It will be shown that a properly chosen combination of PIM-1 and MOF yields unprecedented high permeability, with a performance far above the upper bound, and this performance is maintained upon aging and for gas mixtures, yet at lower permeability and even higher selectivity.

\section{Experimental}

\subsection{Materials}

All starting materials and solvents were purchased from Sigma-Aldrich, except for 5,5',6,6'tetrahydroxy-3,3,3',3'-tetramethyl-1,1'-spirobisindane (TTSBI, Alfa, 98\%), tetrafluoroterephthalonitrile (TFTPN, Apollo Scientific Ltd., 97\%), anhydrous potassium carbonate (Fisher Chemical), sodium hydroxide (Fisher Chemical) and chromium nitrate nonahydrate $\left(\mathrm{Cr}\left(\mathrm{NO}_{3}\right)_{3} \cdot 9 \mathrm{H}_{2} \mathrm{O}\right.$, Alfa, 98\%). All chemicals were used as received, apart from the following chemicals: TTSBI was dissolved in methanol and re-precipitated from dichloromethane before use. TFTPN was purified by sublimation under vacuum before use. Single gases were supplied by Pirossigeno at a minimum purity of $99.9995 \%$. 


\section{$2.2 \quad$ PIM-1 syntheses}

Two different batches of PIM-1 (PIM-1A and PIM-1B) were synthesized from TTBSI and TFTPN by a step polymerization involving a double aromatic nucleophilic substitution with $\mathrm{K}_{2} \mathrm{CO}_{3}$ at $65{ }^{\circ} \mathrm{C}$ for PIM-1A and $160{ }^{\circ} \mathrm{C}$ for PIM-1B as described previously [5,7,41] and detailed in the SI. PIM-1A has $M_{\mathrm{w}}=97,800, M_{\mathrm{n}}=31,100 \mathrm{~g} \mathrm{~mol}^{-1}$ and a polydispersity $M_{\mathrm{w}} / M_{\mathrm{n}}$ $=31$ and PIM-1B has $M_{\mathrm{w}}=112,000, M_{\mathrm{n}}=48,600 \mathrm{~g} \mathrm{~mol}^{-1}$ and a polydispersity $M_{\mathrm{w}} / M_{\mathrm{n}}=2.3$.

\subsection{MOF syntheses}

MIL-101: Two samples of MIL-101 were prepared, the first MIL-101A using a HF-based method as described previously $[40,42]$ and the second MIL-101B using a HF-free method as reported previously [43]. The framework structure of the materials differs slightly in that some $\mathrm{Cr}$ atoms have terminally bound fluoride ions in the former that are replaced by hydroxide ions in the latter. Full synthesis and activation details are provided in the SI.

NanoMIL-101: NanoMIL-101 was prepared following the method of Jiang et al. [44] and full synthesis and activation details are provided in the SI.

ED-MIL-101: ED-MIL-101 was synthesized by functionalising MIL-101B through coordination of the amine groups of ethylene diamine to coordinatively unsaturated chromium sites following a previously reported method [45] and full synthesis and activation details are provided in the SI.

NH H $_{2}$ ML-101: $\mathrm{NH}_{2}$-MIL-101 is MIL-101 synthesized using 2-aminoterephthalic acid instead of terephthalic acid. The sample was prepared using a method based upon the work of Lin et al. [46] and the full synthesis and activation details are provided in the SI.

A<smiles>Cc1c(C)c(C#N)c2c(c1C)Oc1cc3c(cc1O2)C1(CC(C)(C)c2cc4c(cc21)OCO4)CC3(C)C</smiles>

$\mathrm{C}$
B

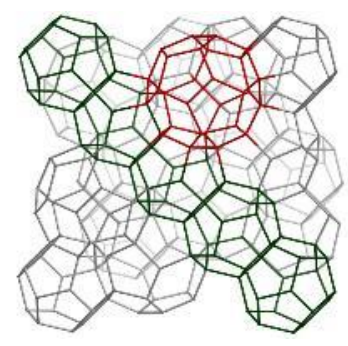

$\mathrm{D}$ 


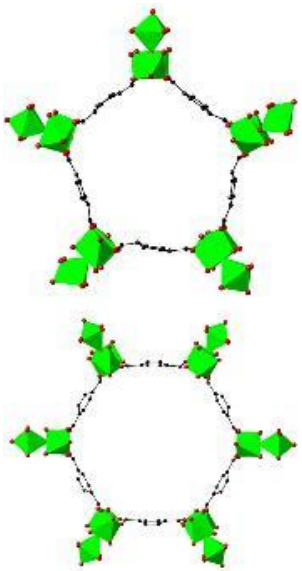

Fig. 1. (A) Repeat unit of PIM-1. (B) Porous structure of MIL-101. (C) Pentagonal and hexagonal nanometre diameter rings of MIL-101. (D) Photograph of a representative PIM-1/MIL101 MMM.

\subsection{Membrane preparation and conditioning}

All the pure PIM-1 and MMMs were cast from chloroform-based solutions or suspensions that were poured into level Petri dishes and then placed in a desiccator. Slow solventevaporation yielded self-standing films that were green in colour for all the MMMs, as exemplified in Fig. 1D. Further details of the membrane preparations are given in the SI. The PIM-1/filler weight ratios were 10:1, 10:2, 10:3 and 10:4, corresponding to filler weight percentages of $9.1 \mathrm{wt} \%, 16.6 \mathrm{wt} \%, 23.1 \mathrm{wt} \%$ and $28.6 \mathrm{wt} \%$, respectively. The volume fractions are calculated by SI Eq. 2 from the polymer and filler weight fractions and their respective densities (see SI Table 1) and the results are given in SI Table 3. As-cast membranes and membranes treated with methanol (PIM-1B/MIL-101B, PIM-1B/ED-MIL101, PIM-1B/NH 2 -MIL-101) or ethanol (PIM-1A/MIL-101A, PIM-1A/NanoMIL-101) were tested. Alcohol treatment involved soaking the membranes for $24 \mathrm{~h}$ in anhydrous methanol or ethanol, followed by drying of the membrane for $24 \mathrm{~h}$ at $25^{\circ} \mathrm{C}$ and ambient pressure. The membranes reported in this work are listed in SI Table 3. Membranes for aging studies were kept at ambient conditions without any control of humidity or air exposure. 


\subsection{Materials and membranes characterization}

Materials and membranes were characterized by gel permeation chromatography (Multi Detector GPC Viscotek 2001 with two Polymer Laboratories mixed bed columns), gas sorption analysis (Micrometrics ASAP 2020 sorption analyzer), scanning electron microscopy (SEM) (Phenom Pro X desktop SEM, Phenom-World and FEI Quanta 200 ESEM) and powder X-ray diffraction (Panalytical X' Pert Pro diffractometer Model PW3040/60). Gas permeation tests of single gases were carried out at $25{ }^{\circ} \mathrm{C}$ and at a feed pressure of 1 bar, using a fixed-volume pressure increase instrument (ESSR), described elsewhere [47]. Permeability coefficients, $P$, and diffusion coefficients, $D$, were determined by the time-lag method [48]. The simplest model of permeation through dense polymeric films describes permeability as the product of a diffusion coefficient and a solubility coefficient. Thus, the apparent solubility, $S$, was indirectly calculated as $S=P / D$. The ideal selectivity for a pair of gases is the ratio of the permeability of the two species, $\alpha_{(\mathrm{A} / \mathrm{B})}=$ $P_{\mathrm{A}} / P_{\mathrm{B}}$. The values reported in the present work are effective values for the MMMs, averaged out over the polymeric and dispersed phases. Mixed gas permeation tests were carried out using a custom made constant pressure/variable volume instrument, described elsewhere [49], equipped with a quadrupole mass filter (HPR-20 QIC Benchtop residual gas analysis system, Hiden Analytical).

\section{Results and discussion}

\subsection{Morphological characterization of MMMs}

SEM images of the cross-section of the MMMs indicate that in general no significant sedimentation takes place and a good homogeneous dispersion of the MOF particles is achieved.
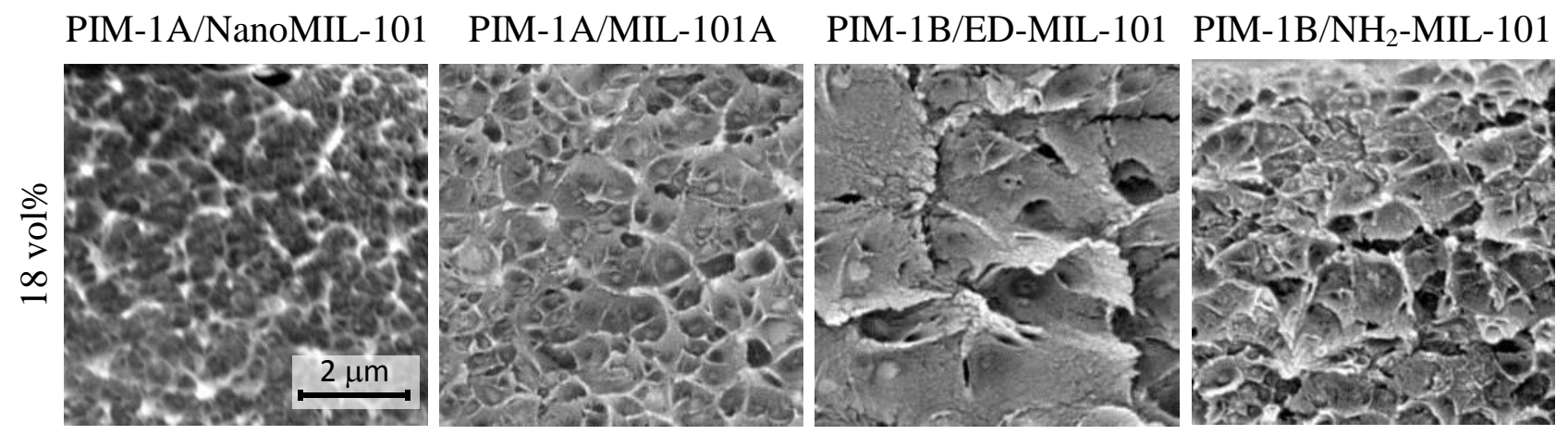

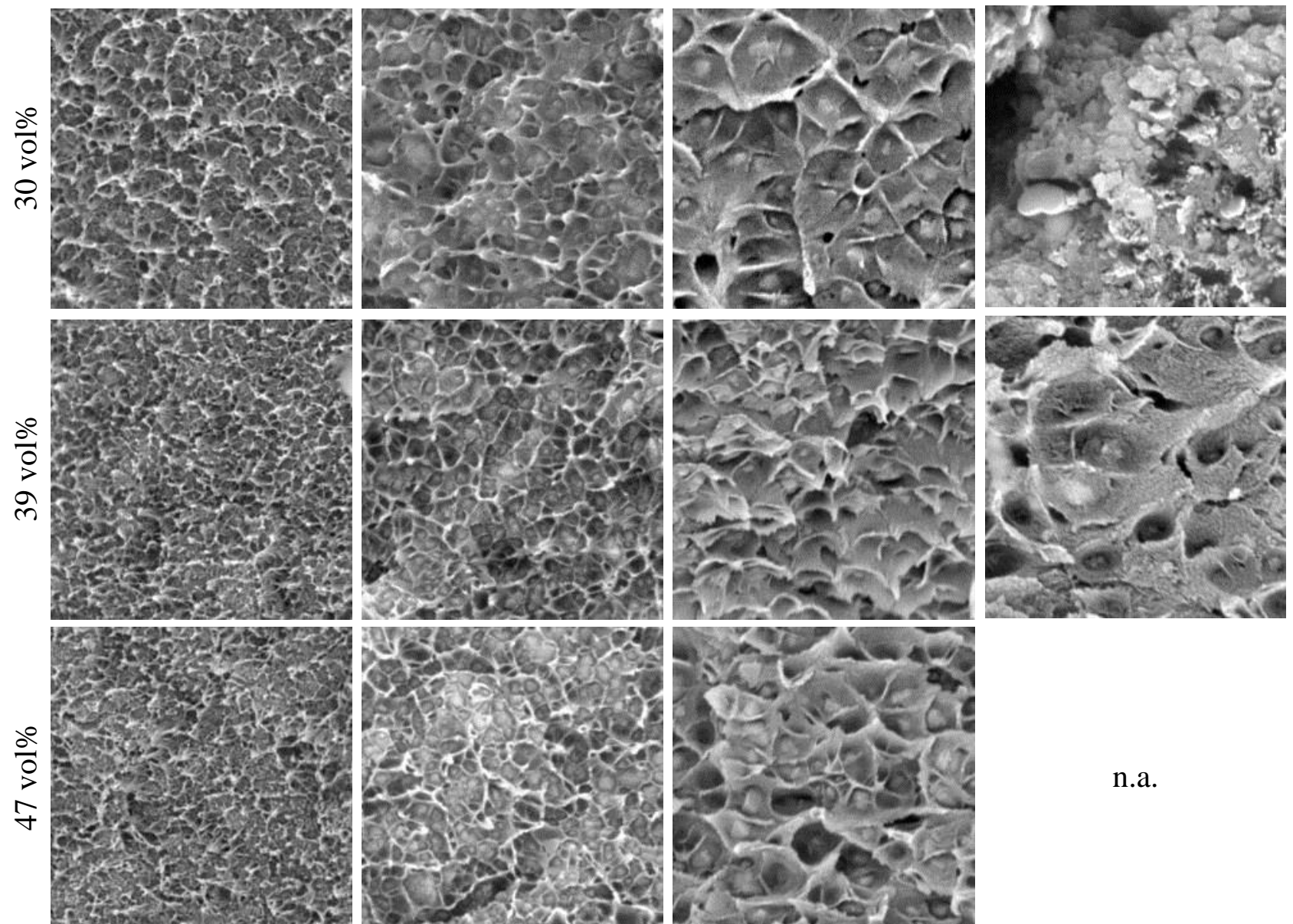

Fig. 2: SEM images of the MMMs of PIM-1A/NanoMIL-101, PIM-1A/MIL-101A, PIM-1B/EDMIL-101 and PIM-1B/ $\mathrm{NH}_{2}-\mathrm{MIL}-101$ with different MOF loadings at a magnification of 40,000 $\mathrm{x}$ and an accelerating voltage of $10 \mathrm{kV}$. The indicated scale bar is identical for all membranes.

Even when the MOF concentration increased from 18 vol\% to the highest $47 \mathrm{vol} \%$, the samples showed no significant agglomeration (Fig. 2 and SI Fig. 4 and SI Fig. 5). Moreover, the SEM images do not show evidence of macro-defects, indicating a good interaction between the fillers and the polymer matrix. The polymer completely surrounds the MOF particles with circular cavities observed in the MMMs. In a few cases the MIL-101 particles seem to be embedded in an open void, but from the deformation of the polymer around these voids, it may be deduced that they are formed as a result of the tensile forces during sample fracture. 


\subsection{Pure gas transport properties}

\subsubsection{Comparison of different MOFs}

Single gas permeation data were measured on the MMMs at $25^{\circ} \mathrm{C}$ in the order $\mathrm{He}, \mathrm{H}_{2}, \mathrm{O}_{2}$, $\mathrm{N}_{2}, \mathrm{CH}_{4}$ and $\mathrm{CO}_{2}$. All permeability, diffusivity and (indirectly calculated) solubility data are given in the supporting information (SI Table 4 - SI Table 8). Permeation tests were carried out on the as prepared MMMs and after alcohol treatment, which is known to open up the polymer structure and to remove residual solvent, resulting in a drastic increase of permeability [7] with similar effects for methanol and ethanol [34]. Alcohol is expected to remove also the residual solvent from MIL-101, which has sufficiently large windows and internal cavities to allow easy access of the alcohol. The permeability indeed increases upon alcohol treatment (Fig. 3). This increase in permeability is mostly due to an increase in diffusion coefficient (See SI Fig. 7) confirming that MIL-101 has sufficiently large windows and internal cavities to allow easy access of the alcohol, in order to promote the removal of residual solvent from MIL-101 and the further passage of the gases (See SI Fig. 7 and SI Table 4 - SI Table 8).

The PIM-1A/MIL-101A membranes show a higher permeability compared to the PIM1A/NanoMIL-101, PIM-1B/NH 2 -MIL-101 and PIM-1B/ED-MIL-101. The effect of MIL-101 in PIM-1 is also larger than that of ZIF-8 and UiO-66 observed previously [34,35]. This is related to the very high surface area of MIL-101 and the large internal voids. The PIM1/MIL-101-based MMMs maintain the same gas permeation order of PIM-1 itself, with $\mathrm{CO}_{2}$ as the most permeable species. An increasing volume fraction of MIL-101A, NanoMIL-101 and MIL-101B results in a higher permeability for all gases (Fig. 3A). This is in agreement with the tendency reported by Naseri et al. for Matrimid ${ }^{\odot} / \mathrm{MIL}-101$ [50] and by Alentiev et al.[29] for PIM-1/MIL-101, which with a loading of only 33\% of MIL-101 increased the $\mathrm{CO}_{2}$ permeability of the neat PIM-1 about 3 fold. On the other hand, ED-MIL-101 and $\mathrm{NH}_{2}$-MIL101 only moderately increased the permeability of neat PIM-1B. This trend is similar to that observed by Ma et al. [51], who reached a maximum loading of only $15 \mathrm{vol} \% \mathrm{NH}_{2}$-MIL-101 and remarkably found a 3 times lower permeability. A decrease of the permeability of the alcohol treated PIM-1 membranes in the presence of $\mathrm{NH}_{2}$-MIL-101 was also observed by Isaeva et al.[52]. Also $\mathrm{NH}_{2}$-modified $\mathrm{UiO}$ and $\mathrm{NH}_{2}$-modified Porous Organic Polymers (POP) give only a modest increased in permeability of PIM-1, similar to those achieved with $\mathrm{NH}_{2}$-MIL-101 [53,54]. ED-MIL-101 does not give any improvement of the PIM-1 
permeability, and over the entire composition range, the membranes with ED-MIL-101 are less permeable than those with $\mathrm{NH}_{2}$-MIL-101, probably due to a larger steric hindrance by the longer ethylenediamine groups.
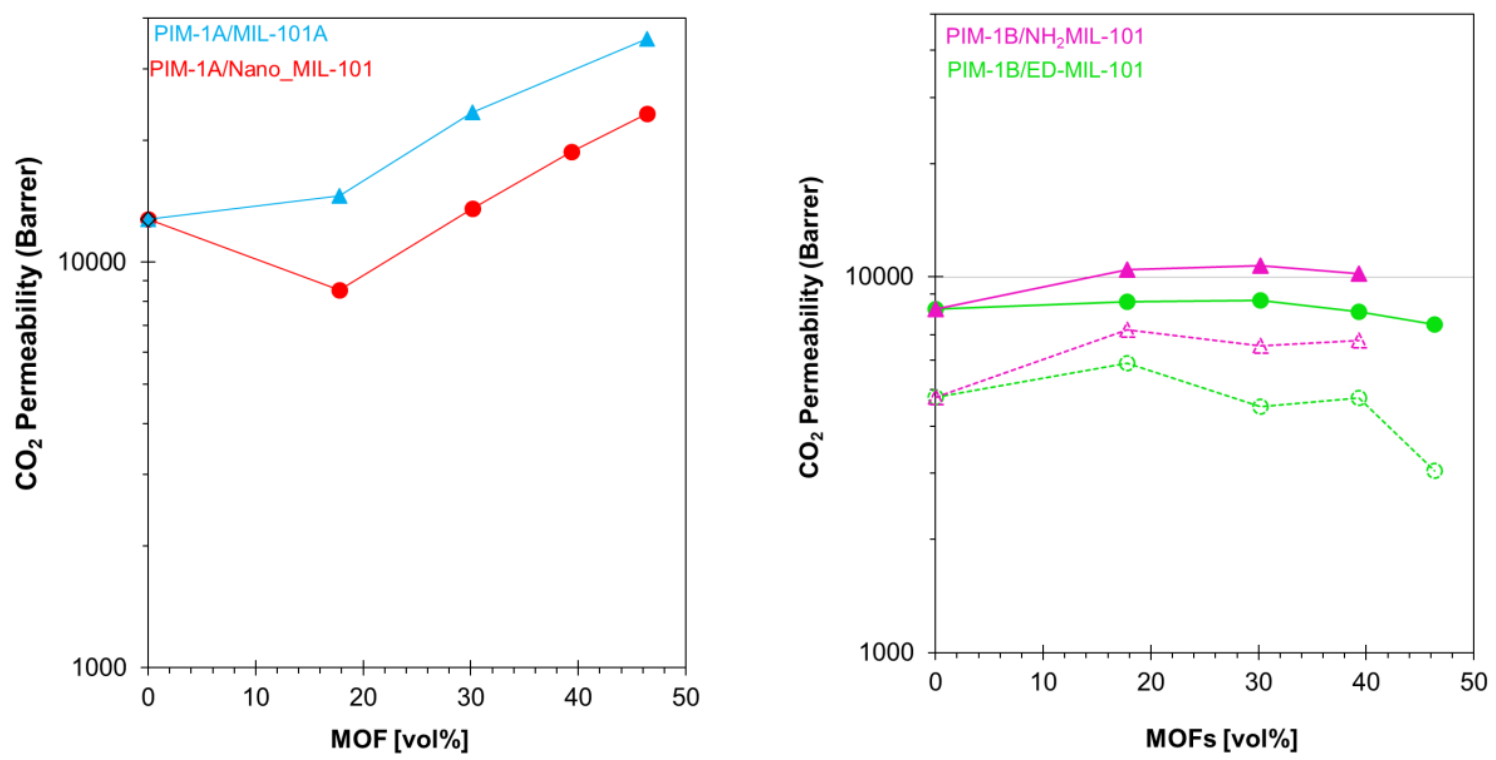

Fig. 3. (A) $\mathrm{CO}_{2}$ permeability coefficient of PIM-1 loaded with MIL-101 ( $\Delta$ ) and NanoMIL101(@) and (B) PIM-1B with $\mathrm{NH}_{2}$-MIL-101(৫) and ED-MIL-101(○). Filled symbols for "as cast" and open symbols for alcohol treated membranes.

The changes in permeability induced by the MOFs are mostly caused by an increase in the diffusion coefficient, which clearly increases with the MIL-101 concentration (SI Fig. 7), and a slight reduction of the solubility (SI Table 4 - SI Table 8). The enhanced diffusion for NanoMIL-101, MIL-101A and MIL-101B indicates transport within the pore structure of the crystalline MOF. Both the as-cast (SI Fig. 7) and the alcohol-treated membranes (Fig. 3A) have a substantially higher permeability with MIL-101 A than with the equivalent NanoMIL101. The lower permeability of the NanoMIL-101 samples suggests the presence of a densified interface layer that hinders access to the internal voids. Instead, at higher loadings, the internal voids in the unfunctionalized MIL-101 crystals and/or inter-crystal voids start dominating the transport properties, so that the permeability tends to increase gradually with increasing filler loading. A similar increase was previously observed for PIM-1 containing ZIF-8 [34] and purely organic cage molecules as porous fillers [55]. 

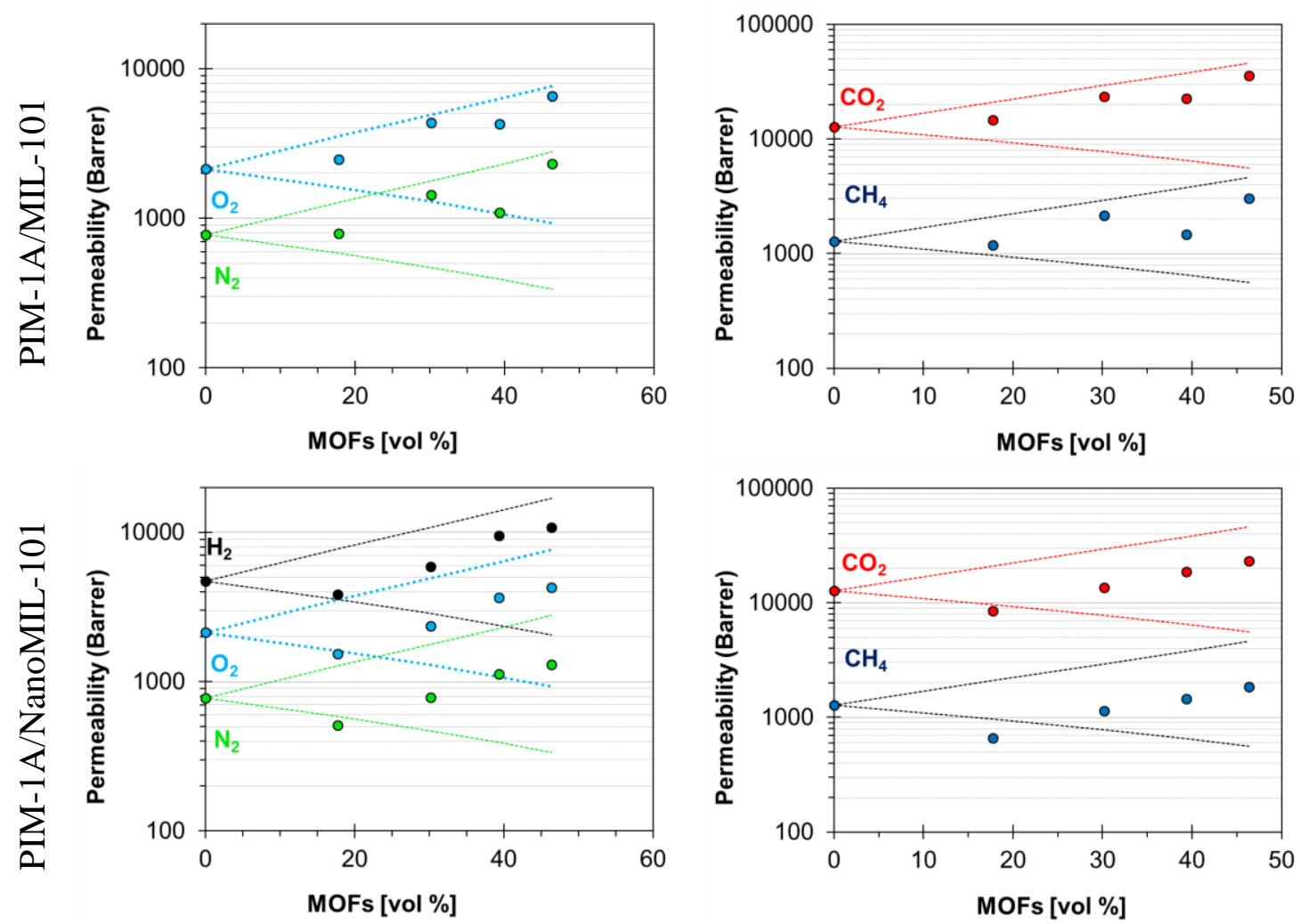

Fig. $4 \mathrm{H}_{2}, \mathrm{O}_{2}, \mathrm{~N}_{2}, \mathrm{CO}_{2}, \mathrm{CH}_{4}$ permeabilities as function of the MOFs concentrations for PIM1A/MIL-101 (top) and PIM-1A/NanoMIL-101 membranes (bottom). The lines represent the upper limit $\left(P_{\mathrm{d}}=\infty\right)$ and lower limit $\left(P_{\mathrm{d}}=0\right)$ of of the Maxwell equation (SI Eq. 3 and SI Eq. 4), respectively. 1 Barrer $=10^{-10} \mathrm{~cm}_{\text {STP }}^{3} \mathrm{~cm} \mathrm{~cm}^{-2} \mathrm{~s}^{-1} \mathrm{cmHg}^{-1}$

Fig. 4 shows the experimental permeabilities of $\mathrm{CO}_{2}$ as a function of the concentration for the most significant MOFs, MIL-101 and Nano-MIL-101 MOFs in comparison with the extreme cases of the Maxwell model. The fact that the permeabilities fall within the Maxwell window [35], delimited by the two extreme cases of $P_{\mathrm{d}}=\infty$ and $P_{\mathrm{d}}=0$, indicates that the membranes are essentially defect-free. Slight scatter in the data, especially of the less permeable gases, is due to the inherent difficulty in making very good and homogeneous films from PIMs with dispersed MOFs. The systematically lower permeability at low MIL loadings, in some cases below the Maxwell limit, indicates that the filler also affects the bulk properties of the PIM, probably by occupying the largest free volume elements. At higher loadings, the volume fraction of the MOF exceeds that of the free volume and the positive effect of the MOF dominates the overall properties.

MIL-101A based MMMs, and to a lesser extent those with Nano-MIL-101 and MIL-101B, show unprecedented permeabilities and approach the upper Maxwell limit with increasing MOF loading compared to the neat polymer. On the other hand, for ED-MIL-101 and $\mathrm{NH}_{2-}$ 
MIL-101, the permeabilities of most MMMs fall relatively close to the centre of the interval predicted by the Maxwell equation, which means that the permeability of these MILs is high and close to that of the polymer matrix itself.

\subsubsection{Comparison of different PIM-1 batches}

A consistency check of two structurally identical fillers in structurally the same polymer, but both from different batches and with different polymer $M_{\mathrm{w}}$ (MIL-101A in PIM-1A and MIL101B in PIM-1B), shows different absolute values, but very similar trends (Fig. 5).

This indicates that the absolute values are dictated by the PIM, and the trends are caused by the MOFs. Variability in permeability of PIMs is a well-known fact, as recently shown by Rose et al. with a cloud of data for PIM-1 from different sources in the literature [56]. We may therefore deduce that the different trends in ED-MIL-101 and $\mathrm{NH}_{2}$-MIL-101 must indeed be attributed to the MOF itself and not to the different PIM-1 batches.

A

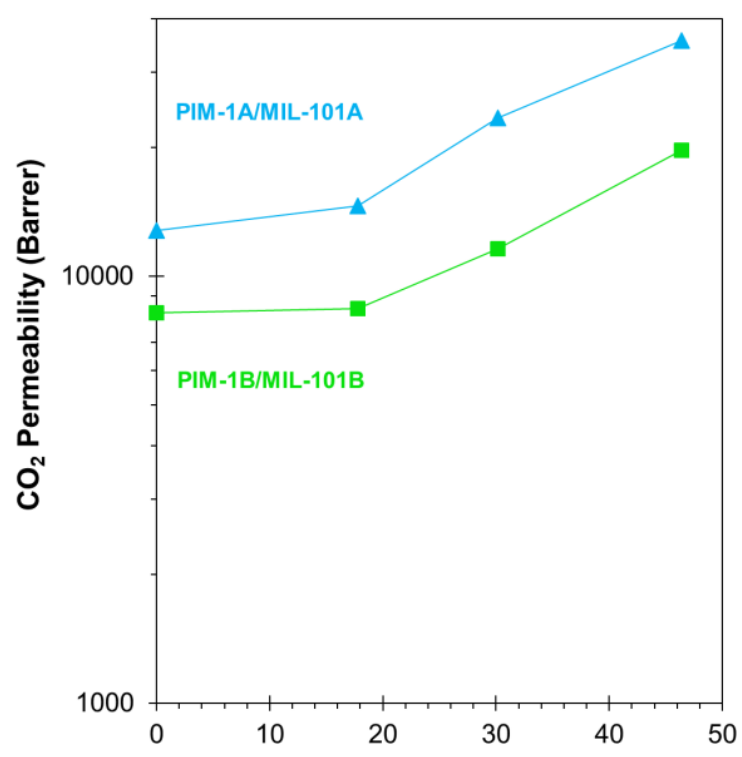

B

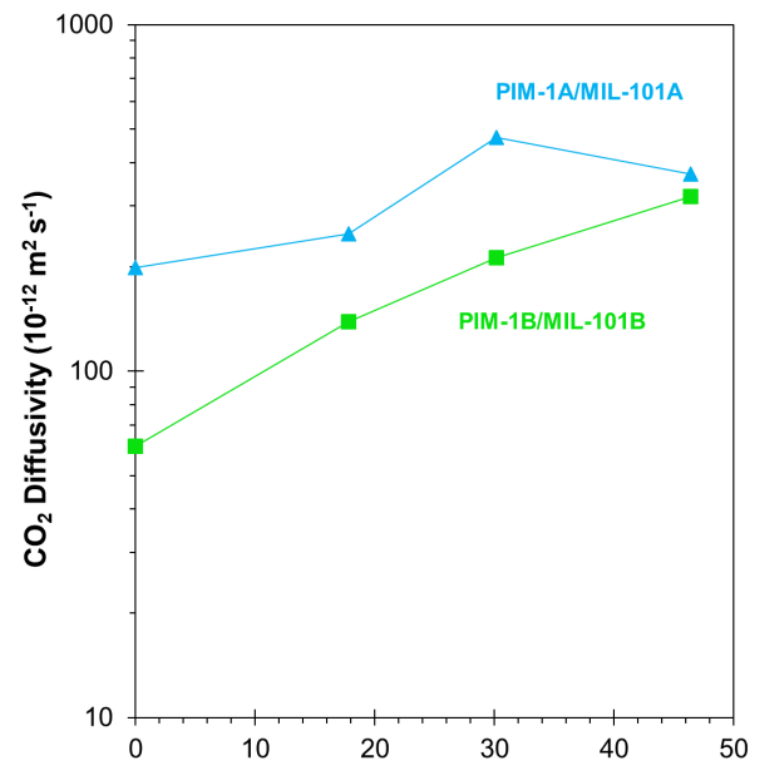

Fig. 5. Similarity of the trends of $\mathrm{CO}_{2}$ permeabilities (A) and diffusion coefficient (B) as function of MIL-101 vol\% loaded in PIM-1A and PIM-1B membranes.

\subsubsection{Aging studies}

Typically, amorphous glassy polymers relax over time, losing excess free volume, and hence permeability. PIMs, with their high free volume, are particularly sensitive to this. On aging, alcohol-treated PIM-1 loses much of the extra permeability gained on alcohol-treatment, both 
for gases $[9,55,57]$ and for vapours [58]. In contrast, the void structure within the crystalline MOF should be stable, provided that no chemical changes or irreversible adsorption occur. Long-term aging studies were therefore performed on the most interesting set of MMMs based on MIL-101 and NanoMIL-101, because it was expected that the presence of MIL-101 might lead to similar stabilization of the permeability as with PAF fillers [20]. This stabilization was, however, not observed and the PIM-1/MIL-101 MMMs of the present work were found to lose permeability over time, coupled with a gain in selectivity. Fig. 6 shows the $\mathrm{CO}_{2}$ permeability as a function of time for the two best performing PIM-1A/MIL-101A and PIM-1A/NanoMIL-101 MMMs after alcohol treatment.

A

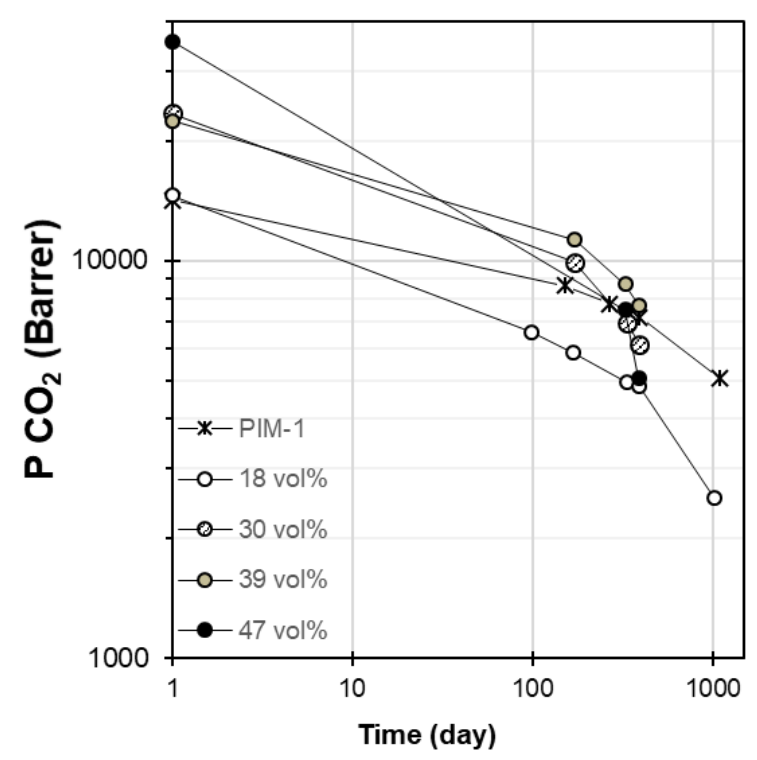

B

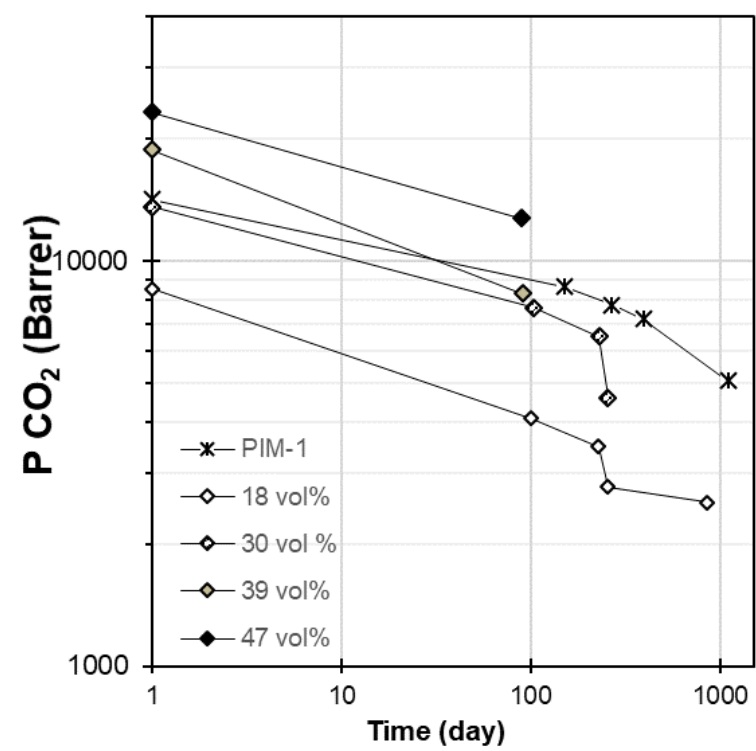

Fig. 6. Change in $\mathrm{CO}_{2}$ permeability over time for A) ethanol-treated PIM-1 (*), PIM1A/MIL-101A MMMs with $18(\mathrm{O}), 30(\bullet), 39(\bigcirc)$ and 47vol\%(○), and B) PIM1A/NanoMIL-101 MMMs with wt. ratios $18(\diamond), 30(\diamond), 39(\diamond)$ and $47 \mathrm{vol} \%(\diamond)$.

For both MIL-101 sizes, all loadings undergo a relatively similar decrease in permeability upon aging. In any case, the rate of physical aging is much slower than that in the ultrapermeable PTMSP, which loses up to two orders of magnitude in permeability for oxygen and isobutane in 100 days [59]. Furthermore, samples with a higher initial permeability maintained this advantage over time and maintained a higher permeability than the as-cast samples. These results demonstrate that the incorporation of MIL-101 may not avoid physical aging, but it can markedly enhance the gas permeability of PIM-1 over short to medium time 
aging, while increasing $\mathrm{CO}_{2} / \mathrm{N}_{2}$ and $\mathrm{CO}_{2} / \mathrm{CH}_{4}$ selectivity (as will be discussed in the next section).

\subsection{Mixed gas transport properties}

The real membrane performance for two relevant industrial separations was tested via mixed gas permeability measurements on the PIM-1A/MIL-101A sample with the highest MOF loading (47 vol\%) and the highest permeability. In order to evaluate the true effect of the MOFs on the transport properties, a well-consolidated as-cast sample after 7 years of aging was tested. This sample is more representative for commercial membranes, which are normally asymmetric or thin film composite membranes, and therefore not alcohol treated. Thin films also age faster, so that the 7 years aged thick film represents a thin film with intermediate age. Measurements were performed from 1 to 6 bar(a) with two binary gas mixtures of $\mathrm{CO}_{2} / \mathrm{N}_{2}(15: 85 \mathrm{vol} \%)$ and $\mathrm{CO}_{2} / \mathrm{CH}_{4}$ (35:65 vol\%), simulating flue gas and biogas, respectively (Fig. 7).

A

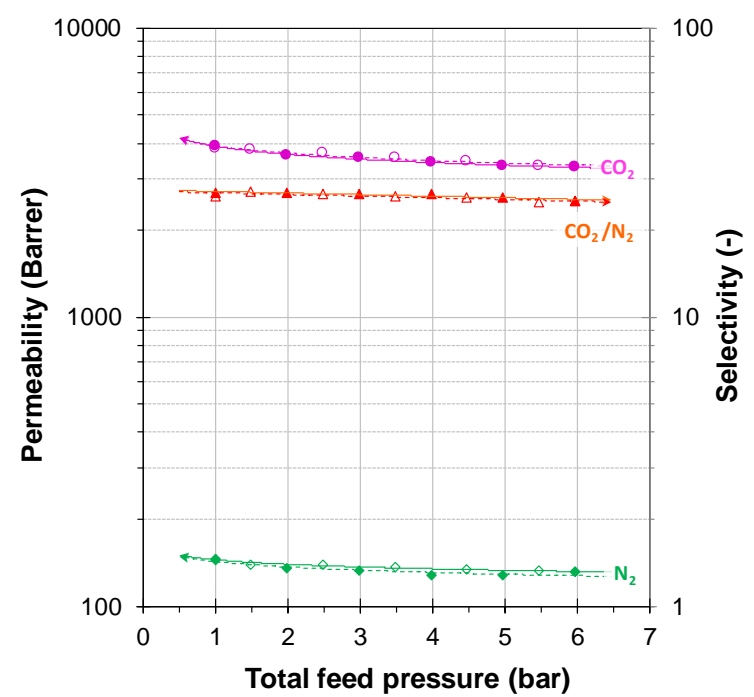

B

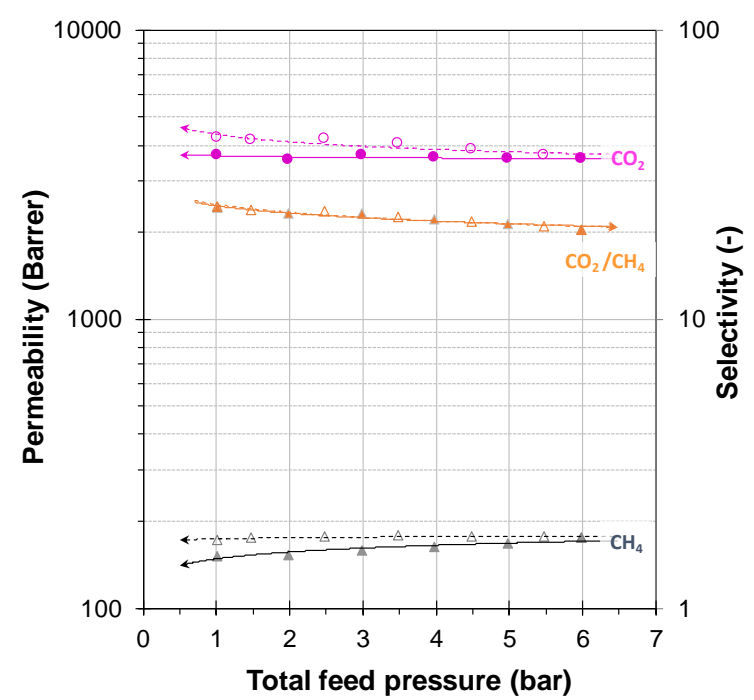

Fig. 7. A) Pressure dependence of $\mathrm{CO}_{2}$ and $\mathrm{N}_{2}$ permeabilities and $\mathrm{CO}_{2} / \mathrm{N}_{2}$ selectivity in binary mixture conditions for $\mathrm{CO}_{2} / \mathrm{N}_{2}(15: 85 \mathrm{vol} \%)$; B) Pressure dependence of $\mathrm{CO}_{2}$ and $\mathrm{CH}_{4}$ permeabilities and $\mathrm{CO}_{2} / \mathrm{CH}_{4}$ selectivity using the binary $\mathrm{CO}_{2} / \mathrm{CH}_{4}(35: 65 \mathrm{vol} \%)$ mixture for the PIM-1A/MIL-101A (47 vol\%) membrane aged for 7 years. Closed symbols for stepwise increase of the pressure and open symbols for the subsequent stepwise decrease of the pressure. 
The synthetic flue gas mixture shows typical dual mode behaviour, with a decrease of $\mathrm{CO}_{2}$ permeability as a function of the feed pressure. Occupation of the free volume by $\mathrm{CO}_{2}$ causes a simultaneous and slightly smaller decrease of the $\mathrm{N}_{2}$ permeability, and as a result, the selectivity slightly decreases as a function of pressure. For this mixture, there is no significant hysteresis between the pressure increase run and the pressure decrease run. On the contrary, anomalous behaviour is observed for the $\mathrm{CO}_{2} / \mathrm{CH}_{4}$ mixture. Competition between dual mode behaviour (with decreasing permeability as a function of pressure) and dilation by the high internal $\mathrm{CO}_{2}$ and $\mathrm{CH}_{4}$ concentrations, gives an almost constant permeability in the pressure increase run, followed by the typical dual mode behaviour on the return run. This clear hysteresis is also observed for methane, but in this case, the dilation facilitates the permeation of methane, which increases with increasing pressure and then remains virtually constant with decreasing pressure. As a consequence, the $\mathrm{CO}_{2} / \mathrm{CH}_{4}$ selectivity decreases with increasing pressure. For both mixtures, the mixed gas performance is better than the ideal selectivity measured in the time lag instrument (see Robeson plot, Fig. 8). This can be ascribed to competitive sorption of $\mathrm{CO}_{2}$ over the less soluble gases $\mathrm{N}_{2}$ and $\mathrm{CH}_{4}$. Although the data move back towards the Robeson upper bound at higher pressure, all mixed gas permeation data lie above the upper bound, confirming the excellent performance of the PIM1A/MIL-101A based MMM.

\subsection{Performance overview}

The results are summarized in the Robeson diagrams in Fig. 8. Alcohol-treated PIM-1A/MIL$101 \mathrm{~A}$ membranes exhibit an extremely high $\mathrm{CO}_{2}$ permeability (up to 35,600 Barrer for 47 vol\% MIL-101). This is within the range of poly(1-trimethylsilyl-1-propyne) (PTMSP), one of the most permeable polymers reported in the literature so far [60-62], but at much higher selectivity, and it is similar to the recently reported triptycene-based PIM [63]. The $\mathrm{CO}_{2} / \mathrm{CH}_{4}$ and $\mathrm{CO}_{2} / \mathrm{N}_{2}$ separation performance of the MMMs surpasses the Robeson upper bound in the high permeability region for MIL-101 and NanoMIL-101. The permeabilities and ideal selectivities shift slightly upward into the righthand direction of the Robeson diagrams, suggesting that the polymer matrix still provides the main resistance to transport, while the fillers provide a preferential diffusion path. This effect is most evident with the larger MIL101 particles, which shows a higher permeability for all gases compared to the NanoMIL-101 (Fig. 8). The initial reduction in permeability compared to the neat PIM-1A at the lowest NanoMIL-101 loading (18 vol\%) can be ascribed to the matrix densification near the 
interface, described by Moore and Koros as case I [64], or to the occupation of the largest free volume elements, as described in section 3.2.1.

A

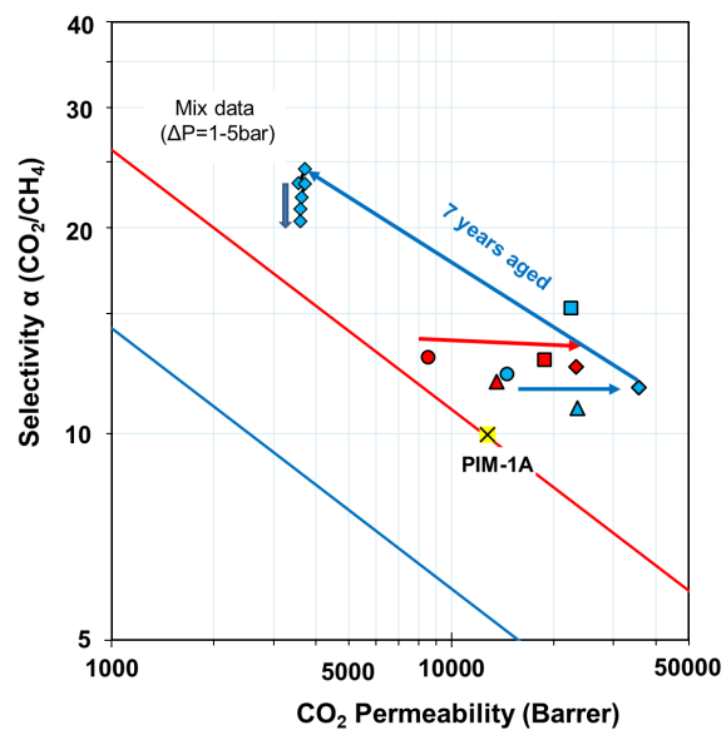

$\mathrm{C}$

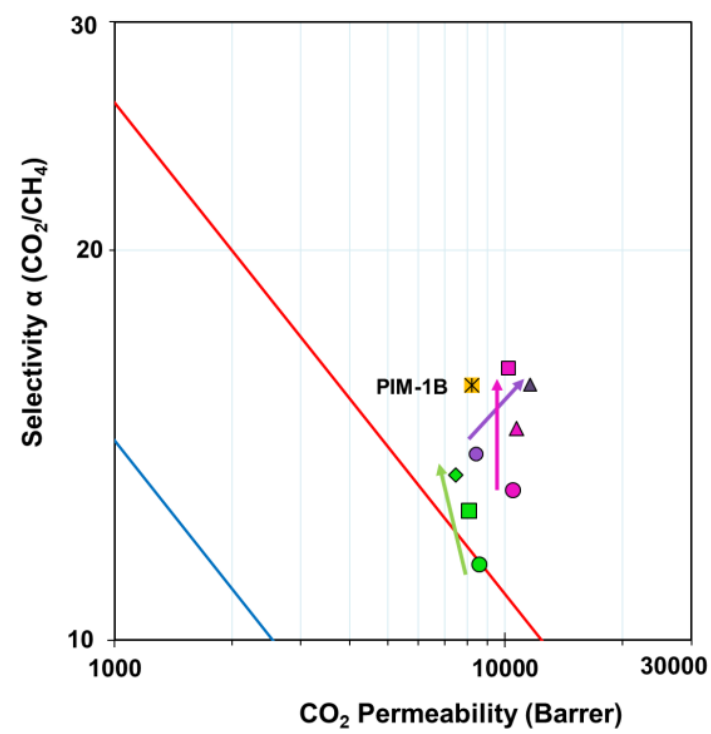

B

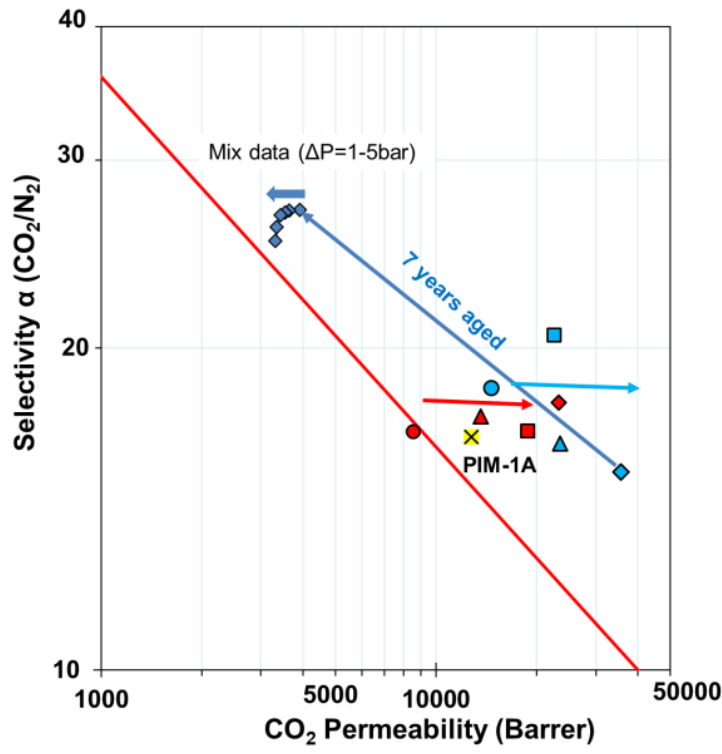

$\mathrm{D}$

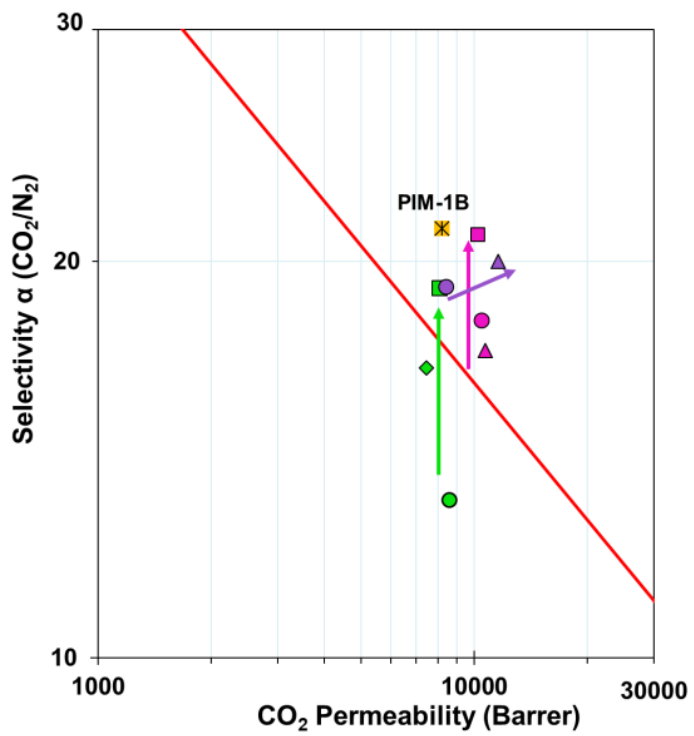

Fig. 8. Robeson's plots of $\mathrm{CO}_{2} / \mathrm{CH}_{4}(\mathrm{~A}, \mathrm{C})$ and $\mathrm{CO}_{2} / \mathrm{N}_{2}$ gas pairs (B,D), showing the data of ethanol treated membranes PIM-1A/MIL-101A (blue) PIM-1A/NanoMIL-101 (red), and methanol treated membranes PIM-1B/NH 2 -MIL-101 (pink), PIM-1B/ED-MIL-101 (green) and PIM-1B/MIL-101B (violet), at 18 vol\%

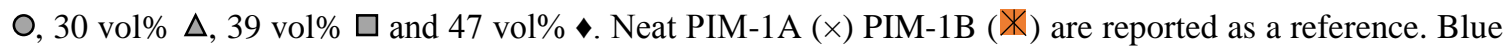
line: 1991 upper bound; red line: 2008 upper bound. [8]. The arrows serve as a guide to the eye to understand the effect of increasing MOF loading. The closely connected blue diamonds represent mixed 
gas data at pressures of 1-6 bar(a) for a 7 years aged PIM-1A/MIL-101A as-cast membrane with a loading of $47 \mathrm{vol} \% .1$ Barrer $=10^{-10} \mathrm{~cm}^{3}[\mathrm{STP}] \mathrm{cm} \mathrm{cm}^{-2} \mathrm{~s}^{-1} \mathrm{cmHg}^{-1}$. Please refer to electronic version for colour figures.

The effect of ED-MIL-101 and $\mathrm{NH}_{2}$-MIL-101 is not fundamentally different, but much smaller, and for most gases there is only a relatively small increase in permeability compared to MIL-101. For $\mathrm{CO}_{2}$, this increase is contrasted by the strong affinity with the amino groups of the functionalized MIL, leading to immobilizing sorption [65,66], as was previously seen for Amine-PIM-1 [67]. Therefore, the permeability of $\mathrm{CO}_{2}$ is relatively constant, and the selectivity of gas pairs involving $\mathrm{CO}_{2}$ decreases. This effect is more evident for ED-MIL-101, which has more amino groups to interact with $\mathrm{CO}_{2}$. Nevertheless, almost all points are still near or above the 2008 Upper Bound for important gas pairs such as $\mathrm{CO}_{2} / \mathrm{CH}_{4}, \mathrm{CO}_{2} / \mathrm{N}_{2}$ and close to the 2015 upper bound for $\mathrm{O}_{2} / \mathrm{N}_{2}$ and $\mathrm{H}_{2} / \mathrm{CH}_{4}$ (SI Fig. 6). The Robeson diagrams highlight especially the impressive mixed gas performance of the aged as-cast membrane sample with permeability and selectivity far exceeding the Robeson upper bound.

\section{Conclusions}

Mixed matrix membranes based on MIL-101, NanoMIL-101, ED-MIL-101 and $\mathrm{NH}_{2}$-MIL101 in the polymer of intrinsic microporosity PIM-1 were successfully obtained and studied for pure and mixed gas permeation. SEM analysis confirmed a good dispersion of the MOFs without evident defects at the interface. After an initial decrease in selectivity in the presence of low concentrations of $\mathrm{NH}_{2}$-MIL-101 and ED-MIL-101, higher concentrations of these fillers restore the ideal gas selectivity to a value close to that of the neat PIM-1B. Nevertheless, they hardly improve the performance of the polymer itself. In contrast, pristine MIL-101 drastically increases the $\mathrm{CO}_{2}$ permeability, maintaining the excellent ideal $\mathrm{CO}_{2} / \mathrm{N}_{2}$ and $\mathrm{CO}_{2} / \mathrm{CH}_{4}$ selectivity of the neat polymer. The effect of MIL-101 samples falls within the range predicted by the Maxwell model for highly permeable fillers. The extremely high $\mathrm{CO}_{2}$ permeability of 35,600 Barrer is an unprecedented achievement for MMMs based on PIM-1. Studies of permeability over time, show that MMMs with large amounts of MOFs maintain a relatively high permeability upon aging compared to neat PIM-1 over short to medium time aging. Finally, under mixed gas permeation tests, an aged as-cast PIM-1/MIL-101 MMM shows better than ideal performance, probably due to competitive sorption. The excellent 
combination of permeability and $\mathrm{CO}_{2} / \mathrm{N}_{2}$ selectivity ( 25-27) and $\mathrm{CO}_{2} / \mathrm{CH}_{4}$ selectivity ( 2124) confirms the potential suitability of the present MMMs for use in relevant industrial gas separations such as biogas purification and $\mathrm{CO}_{2}$ sequestration from flue gas.

\section{Acknowledgements}

The work leading to these results has received funding from the European Union's Seventh Framework Program (FP7/2007-2013) under grant agreement no. 608490, project $\mathrm{M}^{4} \mathrm{CO}_{2}$ and no. 228631, project DoubleNanoMem. MRK received support from the Iraqi Ministry of Higher Education and Scientific Research. AFB was supported by the Engineering and Physical Sciences Research Council (EPSRC) through the Doctoral Training Account. Phenom-World B.V., Eindhoven (NL), is gratefully acknowledged for providing a Phenom Pro X desktop SEM for evaluation.

\section{References}

[1] P. Bernardo, E. Drioli, G. Golemme, Membrane gas separation: A review/state of the art, Ind. Eng. Chem. Res. 48 (2009) 4638-4663. doi:10.1021/ie8019032.

[2] P.M. Budd, N.B. McKeown, Highly permeable polymers for gas separation membranes, Polym. Chem. 1 (2010) 63-68. doi:10.1039/b9py00319c.

[3] N.B. McKeown, P.M. Budd, K.J. Msayib, B.S. Ghanem, H.J. Kingston, C.E. Tattershall, et al., Polymers of intrinsic microporosity (PIMs): Bridging the void between microporous and polymeric materials, Chem. - A Eur. J. 11 (2005) 26102620. doi:10.1002/chem.200400860.

[4] M. Heuchel, D. Fritsch, P.M. Budd, N.B. McKeown, D. Hofmann, Atomistic packing model and free volume distribution of a polymer with intrinsic microporosity (PIM-1), J. Memb. Sci. 318 (2008) 84-99. doi:10.1016/j.memsci.2008.02.038.

[5] P.M. Budd, E.S. Elabas, B.S. Ghanem, S. Makhseed, N.B. McKeown, K.J. Msayib, et al., Solution-Processed, Organophilic Membrane Derived from a Polymer of Intrinsic Microporosity, Adv. Mater. (2004). doi:10.1002/adma.200306053.

[6] P.M. Budd, K.J. Msayib, C.E. Tattershall, B.S. Ghanem, K.J. Reynolds, N.B. Mckeown, et al., Gas separation membranes from polymers of intrinsic microporosity, J. Memb. Sci. 251 (2005) 263-269. doi:10.1016/j.memsci.2005.01.009.

[7] P.M. Budd, N.B. McKeown, B.S. Ghanem, K.J. Msayib, D. Fritsch, L. Starannikova, 
et al., Gas permeation parameters and other physicochemical properties of a polymer of intrinsic microporosity: Polybenzodioxane PIM-1, J. Memb. Sci. 325 (2008) 851860. doi:10.1016/j.memsci.2008.09.010.

[8] L.M. Robeson, The upper bound revisited, J. Memb. Sci. 320 (2008) 390-400. doi:10.1016/j.memsci.2008.04.030.

[9] P. Bernardo, F. Bazzarelli, F. Tasselli, G. Clarizia, C.R. Mason, L. Maynard-Atem, et al., Effect of physical aging on the gas transport and sorption in PIM-1 membranes, Polymer (Guildf). (2016). doi:10.1016/j.polymer.2016.10.040.

[10] Y. Huang, D.R. Paul, Physical aging of thin glassy polymer films monitored by gas permeability, $\quad$ Polymer $\quad$ (Guildf). $45 \quad$ (2004) 8377-8393. doi:10.1016/j.polymer.2004.10.019.

[11] W. S. Harms, K. Rätzke, F. Faupel, N. Chaukura, P.M. Budd, Aging and Free Volume in a Polymer of Intrinsic Microporosity ( PIM-1 ) Aging and Free Volume in a Polymer of Intrinsic Microporosity ( PIM-1 ), J. Adhes. 88 (2012) 37-41. doi:10.1080/00218464.2012.682902.

[12] H. Li, K. Wang, Y. Sun, C.T. Lollar, J. Li, H.-C. Zhou, Recent advances in gas storage and separation using metal-organic frameworks, Mater. Today. 21 (2018) 108-121. doi:10.1016/J.MATTOD.2017.07.006.

[13] R.D. Noble, Perspectives on mixed matrix membranes, J. Memb. Sci. 378 (2011) 393397. doi:10.1016/j.memsci.2011.05.031.

[14] J. Ahn, W.-J. Chung, I. Pinnau, J. Song, N. Du, G.P. Robertson, et al., Gas transport behavior of mixed-matrix membranes composed of silica nanoparticles in a polymer of intrinsic microporosity (PIM-1), J. Memb. Sci. 346 (2010) 280-287. doi:10.1016/j.memsci.2009.09.047.

[15] G. Dong, H. Li, V. Chen, Challenges and opportunities for mixed-matrix membranes for gas separation, J. Mater. Chem. A. 1 (2013) 4610-4630. doi:10.1039/C3TA00927K.

[16] M.A. Rodrigues, J. de S. Ribeiro, E. de S. Costa, J.L. de Miranda, H.C. Ferraz, Nanostructured membranes containing UiO-66 (Zr) and MIL-101 (Cr) for O2/N2and CO2/N2separation, Sep. Purif. Technol. (2018). doi:10.1016/j.seppur.2017.10.024.

[17] Y. Cheng, Z. Wang, D. Zhao, Mixed Matrix Membranes for Natural Gas Upgrading: Current Status and Opportunities, Ind. Eng. Chem. Res. 57 (2018) 4139-4169. doi:10.1021/acs.iecr.7b04796. 
[18] M.A.A. Aroon, A.F.F. Ismail, T. Matsuura, M.M.M. Montazer-Rahmati, Performance studies of mixed matrix membranes for gas separation: A review, Sep. Purif. Technol. 75 (2010) 229-242. doi:10.1016/j.seppur.2010.08.023.

[19] Y. Yampolskii, Polymeric Gas Separation Membranes, 45 (2012) 3298-3311.

[20] C.H. Lau, P.T. Nguyen, M.R. Hill, A.W. Thornton, K. Konstas, C.M. Doherty, et al., Ending aging in super glassy polymer membranes, Angew. Chemie - Int. Ed. 53 (2014) 5322-5326. doi:10.1002/anie.201402234.

[21] L. Olivieri, S. Meneguzzo, S. Ligi, A. Saccani, L. Giorgini, A. Orsini, et al., Reducing ageing of thin PTMSP films by incorporating graphene and graphene oxide: effect of thickness, gas type and temperature, J. Memb. Sci. (2018). doi:10.1016/J.MEMSCI.2018.03.056.

[22] S. Rochat, K. Polak-Kraśna, M. Tian, L.T. Holyfield, T.J. Mays, C.R. Bowen, et al., Hydrogen storage in polymer-based processable microporous composites, J. Mater. Chem. A. 5 (2017) 18752-18761. doi:10.1039/c7ta05232d.

[23] C.R. Mason, M.G. Buonomenna, G. Golemme, P.M. Budd, F. Galiano, A. Figoli, et al., New organophilic mixed matrix membranes derived from a polymer of intrinsic microporosity and silicalite-1, Polym. (United Kingdom). 54 (2013) 2222-2230. doi:10.1016/j.polymer.2013.02.032.

[24] M.M. Khan, V. Filiz, G. Bengtson, M.M. Rahman, S. Shishatskiy, V. Abetz, Functionalized Carbon Nanotube Mixed Matrix Membranes of Polymers of Intrinsic Microporosity (PIMs) for Gas Separation, Procedia Eng. 44 (2012) 1899-1901. doi:http://dx.doi.org/10.1016/j.proeng.2012.08.997.

[25] K. Althumayri, W.J. Harrison, Y. Shin, J.M. Gardiner, C. Casiraghi, P.M. Budd, et al., The influence of few-layer graphene on the gas permeability of the high-free-volume polymer PIM-1, Philos. Trans. R. Soc. A Math. Phys. Eng. Sci. 374 (2016) 20150031. doi:10.1098/rsta.2015.0031.

[26] M.M. Khan, S. Shishatskiy, V. Filiz, Mixed matrix membranes of boron icosahedron and polymers of intrinsic microporosity (PIM-1) for gas separation, Membranes (Basel). 8 (2018) 1-18. doi:10.3390/membranes8010001.

[27] O.M. Yaghi, H. Li, C. Davis, D. Richardson, T.L. Groy, Synthetic Strategies , Structure Patterns, and Emerging Properties in the Chemistry of Modular Porous Solids $\uparrow$ Decorated Diamond Nets : Porous Metal, 31 (1998) 474-484.

[28] O.K. Farha, J.T. Hupp, Activation of Metal - Organic Framework Materials, Chem. 
Res. 43 (2010) 1166-1175.

[29] a. Y. Alentiev, G.N. Bondarenko, Y. V. Kostina, V.P. Shantarovich, S.N. Klyamkin, V.P. Fedin, et al., PIM-1/MIL-101 hybrid composite membrane material: Transport properties and free volume, Pet. Chem. 54 (2014) 477-481. doi:10.1134/S0965544114070020.

[30] R. Castro-Muñoz, V. Fíla, C.T. Dung, Mixed Matrix Membranes Based on PIMs for Gas Permeation: Principles, Synthesis, and Current Status, Chem. Eng. Commun. 204 (2017) 295-309. doi:10.1080/00986445.2016.1273832.

[31] H.B.T. Jeazet, T. Koschine, C. Staudt, K. Raetzke, C. Janiak, Correlation of Gas Permeability in a Metal-Organic Framework MIL-101(Cr)-Polysulfone Mixed-Matrix Membrane with Free Volume Measurements by Positron Annihilation Lifetime Spectroscopy (PALS), 3 (2013) 331-353. doi:10.3390/membranes3040331.

[32] H.B. Tanh Jeazet, C. Staudt, C. Janiak, Metal-organic frameworks in mixed-matrix membranes for gas separation, Dalt. Trans. 41 (2012) 14003-14027. doi:10.1039/c2dt31550e.

[33] A. Fuoco, M. Khdhayyer, M. Attfield, E. Esposito, J. Jansen, P. Budd, Synthesis and Transport Properties of Novel MOF/PIM-1/MOF Sandwich Membranes for Gas Separation, Membranes (Basel). 7 (2017) 1-17. doi:10.3390/membranes7010007.

[34] A.F. Bushell, M.P. Attfield, C.R. Mason, P.M. Budd, Y. Yampolskii, L. Starannikova, et al., Gas permeation parameters of mixed matrix membranes based on the polymer of intrinsic microporosity PIM-1 and the zeolitic imidazolate framework ZIF-8, J. Memb. Sci. 427 (2013) 48-62. doi:10.1016/j.memsci.2012.09.035.

[35] M.R. Khdhayyer, E. Esposito, A. Fuoco, M. Monteleone, L. Giorno, J.C. Jansen, et al., Mixed matrix membranes based on UiO-66 MOFs in the polymer of intrinsic microporosity PIM-1, Sep. Purif. Technol. $173 \quad$ (2017) 304-313. doi:10.1016/J.SEPPUR.2016.09.036.

[36] G. Férey, C. Mellot-Draznieks, C. Serre, F. Millange, J. Dutour, S. Surblé, et al., A chromium terephthalate-based solid with unusually large pore volumes and surface area., Science. 309 (2005) 2040-2042. doi:10.1126/science.1116275.

[37] J.P. Jung, M.J. Kim, Y.S. Bae, J.H. Kim, Facile preparation of $\mathrm{Cu}(\mathrm{I})$ impregnated MIL-101(Cr) and its use in a mixed matrix membrane for olefin/paraffin separation, J. Appl. Polym. Sci. 135 (2018) 1-8. doi:10.1002/app.46545.

[38] W. Zhang, Y. Ying, J. Ma, X. Guo, H. Huang, D. Liu, et al., Mixed matrix membranes 
incorporated with polydopamine-coated metal-organic framework for dehydration of ethylene glycol by pervaporation, J. Memb. Sci. 527 (2017) 8-17. doi:10.1016/J.MEMSCI.2017.01.001.

[39] H.B. Tanh Jeazet, S. Sorribas, J.M. Román-Marín, B. Zornoza, C. Téllez, J. Coronas, et al., Increased Selectivity in CO2/CH4Separation with Mixed-Matrix Membranes of Polysulfone and Mixed-MOFs MIL-101(Cr) and ZIF-8, Eur. J. Inorg. Chem. 2016 (2016) 4363-4367. doi:10.1002/ejic.201600190.

[40] G. Férey, C. Mellot-Draznieks, C. Serre, F. Millange, J. Dutour, S. Surblé, et al., A Chromium Terephtalate-Based Solid with Unusually Large Pore Volumes and Surface Area, Science (80-. ). 309 (2005) 2040. doi:10.1126/science.1116275.

[41] N. Du, G.P. Robertson, J. Song, I. Pinnau, S. Thomas, M.D. Guiver, Polymers of intrinsic microporosity containing trifluoromethyl and phenylsulfone groups as materials for membrane gas separation, Macromolecules. 41 (2008) 9656-9662. doi:10.1021/ma801858d.

[42] P.L. Llewellyn, S. Bourrelly, C. Serre, A. Vimont, M. Daturi, L. Hamon, et al., High uptakes of $\mathrm{CO} 2$ and $\mathrm{CH} 4$ in mesoporous metal-organic frameworks MIL-100 and MIL-101, Langmuir. 24 (2008) 7245-7250. doi:10.1021/la800227x.

[43] L. Bromberg, Y. Diao, H. Wu, S.A. Speakman, T.A. Hatton, Chromium(III) terephthalate metal organic framework (MIL-101): Hf-free synthesis, structure, polyoxometalate composites, and catalytic properties, Chem. Mater. 24 (2012) 16641675. doi:10.1021/cm2034382.

[44] D. Jiang, A.D. Burrows, K.J. Edler, Size-controlled synthesis of MIL-101(Cr) nanoparticles with enhanced selectivity for CO2 over N2, CrystEngComm. (2011). doi:10.1039/c1ce06274c.

[45] Y.K. Hwang, D.-Y. Hong, J.-S. Chang, S.H. Jhung, Y.-K. Seo, J. Kim, et al., Amine grafting on coordinatively unsaturated metal centers of MOFs: Consequences for catalysis and metal encapsulation, Angew. Chemie - Int. Ed. 47 (2008) 4144-4148. doi:10.1002/anie.200705998.

[46] Y. Lin, C. Kong, L. Chen, Direct synthesis of amine-functionalized MIL-101(Cr) nanoparticles and application for CO\&lt;inf\&gt;2\&lt;/inf\&gt; capture, RSC Adv. 2 (2012) 6417-6419. doi:10.1039/c2ra20641b.

[47] J.C. Jansen, K. Friess, E. Drioli, Organic vapour transport in glassy perfluoropolymer membranes: A simple semi-quantitative approach to analyze clustering phenomena by 
time lag measurements, J. Memb. Sci. 367 (2011) 141-151. doi:10.1016/j.memsci.2010.10.063.

[48] J. Crank, The mathematics of diffusion, 2nd ed., Clarendon Press, Oxford, 1975.

[49] S.C. Fraga, M. Monteleone, M. Lanč, E. Esposito, A. Fuoco, L. Giorno, et al., A novel time lag method for the analysis of mixed gas diffusion in polymeric membranes by on-line mass spectrometry: Method development and validation, J. Memb. Sci. 561 (2018) 39-58. doi:10.1016/J.MEMSCI.2018.04.029.

[50] M. Naseri, S.F. Mousavi, T. Mohammadi, O. Bakhtiari, Synthesis and gas transport performance of MIL-101/Matrimid mixed matrix membranes, J. Ind. Eng. Chem. 29 (2015) 249-256. doi:10.1016/j.jiec.2015.04.007.

[51] J. Ma, Y. Ying, X. Guo, H. Huang, D. Liu, C. Zhong, Fabrication of mixed-matrix membrane containing metal-organic framework composite with task-specific ionic liquid for efficient CO2 separation, J. Mater. Chem. A. 4 (2016) 7281-7288. doi:10.1039/c6ta02611g.

[52] L.M.K. V. I. Isaeva, A. L. Tarasov, a L. E. Starannikova, Yu. P. Yampol'skii, A. Yu. Alent'ev, Microwave assisted synthesis of mesoporous metal organic framework NH2MIL-101(Al), Russ. Chem. Bull. Int. Ed. 64 (2015) 2791-2795.

[53] Z. Wang, H. Ren, S. Zhang, F. Zhang, J. Jin, Polymers of intrinsic microporosity/metal-organic framework hybrid membranes with improved interfacial interaction for high-performance CO2 separation, J. Mater. Chem. A. 5 (2017) 1096810977. doi:10.1039/C7TA01773A.

[54] C. Wang, F. Guo, H. Li, J. Xu, J. Hu, H. Liu, Porous organic polymer as fillers for fabrication of defect-free PIM-1 based mixed matrix membranes with facilitating CO2transfer chain, J. Memb. Sci. $564 \quad$ (2018) 115-122. doi:10.1016/J.MEMSCI.2018.07.018.

[55] A.F. Bushell, P.M. Budd, M.P. Attfield, J.T.A. Jones, T. Hasell, A.I. Cooper, et al., Nanoporous Organic Polymer/Cage Composite Membranes, Angew. Chemie Int. Ed. 52 (2013) 1253-1256. doi:10.1002/anie.201206339.

[56] I. Rose, C.G. Bezzu, M. Carta, B. Comesanã-Gándara, E. Lasseuguette, M.C. Ferrari, et al., Polymer ultrapermeability from the inefficient packing of 2D chains, Nat. Mater. 16 (2017) 932-937. doi:10.1038/nmat4939.

[57] R.R. Tiwari, J. Jin, B.D. Freeman, D.R. Paul, Physical aging, CO2 sorption and plasticization in thin films of polymer with intrinsic microporosity (PIM-1), J. Memb. 
Sci. 537 (2017) 362-371. doi:10.1016/j.memsci.2017.04.069.

[58] K. Pilnáček, O. Vopička, M. Lanč, M. Dendisová, M. Zgažar, P.M. Budd, et al., Aging of polymers of intrinsic microporosity tracked by methanol vapour permeation, J. Memb. Sci. 520 (2016) 895-906. doi:http://dx.doi.org/10.1016/j.memsci.2016.08.054.

[59] H. Shimomura, K. Nakanishi, H. Odani, M. Kurata, T. Masuda, T. Higashimura, Permeation of Gases in Poly[1-(trimethylsiiyl)-1-propyne], KOBUNSHI RONBUNSHU. 43 (1986) 747-753. doi:10.1295/koron.43.747.

[60] T. Masuda, Y. Iguchi, B.Z. Tang, T. Higashimura, Diffusion and solution of gases in substituted polyacetylene membranes, Polymer (Guildf). 29 (1988) 2041-2049. doi:10.1016/0032-3861(88)90178-4.

[61] I. Pinnau, C. G. Casillas, A. Morisato, B. D. Freeman, Hydrocarbon / Hydrogen Mixed Gas Permeation, Polym. Sci. Part B Polym. Phys. 34 (1996) 2613-2621.

[62] Y. Hu, M. Shiotsuki, F. Sanda, B.D. Freeman, T. Masuda, Synthesis and Properties of Indan-Based Polyacetylenes That Feature the Highest Gas Permeability among All the Existing Polymers, Macromolecules. 41 (2008) 8525-8532.

[63] I. Rose, M. Carta, R. Malpass-Evans, M.-C. Ferrari, P. Bernardo, G. Clarizia, et al., Highly Permeable Benzotriptycene-Based Polymer of Intrinsic Microporosity, ACS Macro Lett. 4 (2015) 912-915. doi:10.1021/acsmacrolett.5b00439.

[64] T.T. Moore, W.J. Koros, Non-ideal effects in organic-inorganic materials for gas separation membranes, J. Mol. Struct. $739 \quad$ (2005) 87-98. doi:10.1016/j.molstruc.2004.05.043.

[65] D.R. Paul, Effect of immobilizing adsorption on the diffusion time lag, J. Polym. Sci. Part A-2 Polym. Phys. 7 (1969) 1811-1818. doi:10.1002/pol.1969.160071015.

[66] Z. Grzywna, J. Podkowka, Effect of immobilizing adsorption on mass transport through polymer films, J. Memb. Sci. 8 (1981) 23-31. doi:10.1016/S03767388(00)82136-5.

[67] C.R. Mason, L. Maynard-Atem, K.W.J. Heard, B. Satilmis, P.M. Budd, K. Friess, et al., Enhancement of CO2 Affinity in a Polymer of Intrinsic Microporosity by Amine Modification., Macromolecules. 47 (2014) 1021-1029. doi:10.1021/ma401869p. 